\title{
Potential issues related to emergency core cooling system strainers performance at boiling water reactors: Application to Cofrentes NPP (Spain)
}

\author{
Rafael Rubio Gonzalo Jimenez
}

\begin{abstract}
A B S T R A C T
From the 60s to the 90s, a great number of events related to the Emergency Core Cooling Systems Strainers have been happened in all kind of reactors all over the world. Thus, the Nuclear Regulatory Commission of the USA emitted some Bulletins to address the concerns about the adequacy of Emergency Core Cooling Systems (ECCS) strainer performance at boiling water reactors (BWR). In Spain the regulatory body (Consejo de Seguridad Nuclear, CSN) adopted the USA regulation and Cofrentes NPP installed new strainers with a considerable bigger size than the old strainers. The nuclear industry conducted significant and extensive research, guidance development, testing, reviews, and hardware and procedure changes during the 90s to resolve the issues related to debris blockage of BWR strainers. In 2001 the NRC and CSN closed the Bulletins. Thereafter, the strainers issues were moved to the PWR reactors. In 2004 the NRC issued a Generic Letter (GL). It requested the resolution of several effects which were not noted in the past. The GL regarded to be resolved by the PWR reactors but the NRC in USA and the CSN in Spain have requested that the BWR reactors investigate differences between the methodologies used by the BWRs and PWRs. The developments and improvements done for Cofrentes NPP are detailed. Studies for this plant show that the head loss due to the considered debris is at most half of the limited head loss for the ECCS strainer and the NPSH (Net Positive Suction Head) required for the ECCS pumps is at least three times lower than the NPSH available.
\end{abstract}

\section{Introduction}

\subsection{Background}

In the original regulation, Regulatory Guide 1.82 (NRC, 1974), the " $50 \%$ blockage assumption" was raised. This assumption allows assuming that only half of the vertical screen area was available due to sump blockage in case of an accident.
Subsequently, in 1979, the Unresolved Safety Issue A-43 was opened (NRC, 1979), to take into account problems such as vortex formation, debris blockage and ingestion of debris in pumps. The USI A-43 was close by the Generic Letter 85-22 (NRC, 1985), which was used to update the RG 1.82 .

From the 60 s to the 90 s, a great number of events related to the ECCS strainers had happened in a variety of reactors all over the world, being the most relevant Barsebäck (1992), Perry (1992, 1993), Limerick (1995), Hart (2004) and (NRC, 1995b, 1996).

In response to these events, the Nuclear Regulatory Commission of the USA (NRC) emitted Bulletins 95-02 and 96-03 to address these concerns at BWRs, as it was becoming a preoccupation for 
the Regulator (NRC, 1995). Bulletin 95-02 (NRC, 1995b), resulted in enhanced licensee measures to clean the suppression pools and establish foreign material control programs. Bulletin 96-03 (NRC, 1996) instances to each BWR plant assessing its plant-specific situation regarding potential strainer clogging and recommended the installation of larger passive strainers.

The strainer issues were evaluated very early in the Nordic countries (Hyvarinen, 1995). In conclusion, new designs were implemented in VVER reactors in Finland (Mohsen, 1995) or PWR in Sweden (Henriksson and Schon, 1996; Trybom, 1996).

To provide guidance to operators of BWRs for responding to these Bulletins, the BWR Owners' Group issued Licensing Topical Report NEDO-32686, rev.0 in 1996 (BWROG, 1996). The most relevant modification was that each plant installed significantly larger passive strainers (star, stacked disk or cassette type).

The Spanish regulatory body ( $\mathrm{CSN}$ ) adopted the USA regulation to the Spanish plants, and Cofrentes installed new ECCS strainers with a considerable bigger size than the old ones $\left(200 \mathrm{ft}^{2} \mathrm{vs} 17 \mathrm{ft}^{2}\right)$ in 1999.

In 2001 the NRC closed the action on Bulletins 95-02 and 9603, publishing a report by Los Alamos National Laboratory with the lessons learned and the experimental test results (Rao et al., 2001). One year later the CSN close the action for the bulletins in Spain.

Subsequently, the strainer matter requests were moved to the PWR reactors. In 1996 the NRC issued Generic Safety Issue (GSI)191 (NRC, 1996b), to examine whether the events and new research being conducted for the BWR strainers warranted similar activity at the PWR plants.

In conclusion to all this previous work, the NRC issued the Generic Letter (GL) 2004-02 in 2004 (NRC, 2004). This letter requested the resolution of several effects which were not noted in Bulletins 95-02 and 96-03 as the blockage of the recirculation flow downstream the strainer and the potential for chemical species to develop that could contribute to the debris load.

In parallel, the German Reactor Safety Commission emitted the "Requirements for the demonstration of effective emergency core cooling during loss-of-coolant accidents with release of insulation material and other substances" in July 2004 (Pointer et al., 2008). Caused by that regulation, strainer size and modification of the insulation were implemented in the German plants. In the Taiwanese plant Maanshan NPP, started the evaluation on 2009, according to Cheng (2009).

All the plant affected conducted several studies and design modifications to accomplish with the GL 2004-02. In 2009, the NRC published a communication paper summarizing the lessons learned from the strainer evaluation in light water reactors (NRC, 2009).

In the latest years, many research studies about the strainer blockage have been done. To calculate the ECCS pumps capacity and the influence of the debris blockage, extensive calculation have been performed, both analytical and with CFDs, see Grahn et al. (2008), Krepper et al. (2008, 2009, 2011), and Bahn et al. (2009, 2011 a,b).

Some more research work has been done on the impact of the sump clogging during accidental conditions, see Sandrine et al. (2008) or Lee et al. (2011).

\subsection{Plant description}

Cofrentes Nuclear Power Plant is a Boiling Water Reactor (BWR/6, Mark III Containment) designed and supplied by GE. The plant is inland, located $64 \mathrm{~km}$ far from the city of Valencia in the East of Spain and is owned by Iberdrola Generación S.A.

The plant was firstly connected to the national grid in 1984 . At that time the thermal power of the plant was $2894 \mathrm{MWt}$.

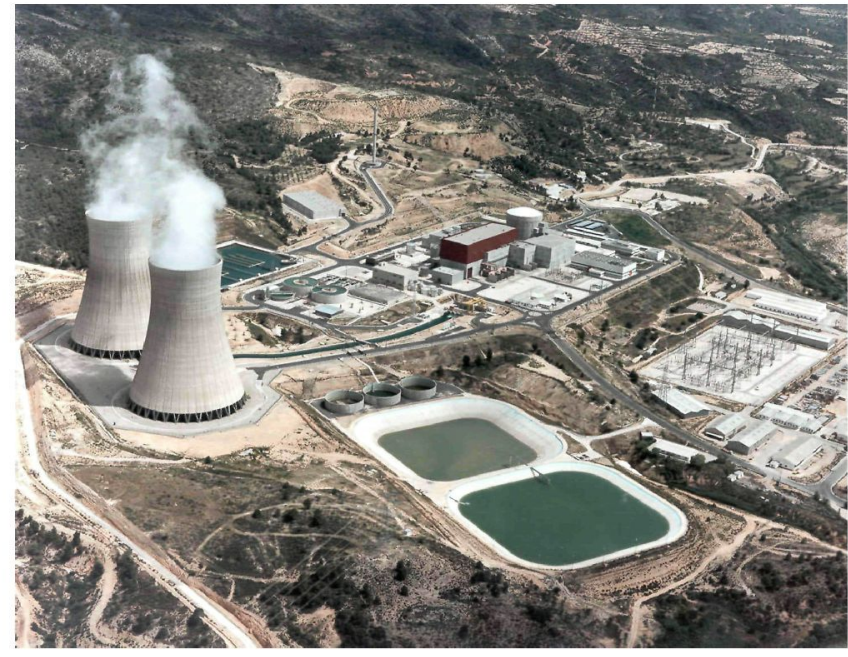

Fig. 1. Overview of Cofrentes NPP.

After several upratings, the licensed power nowadays is $3237 \mathrm{MWt}$ (111.85\%).

An overview of the plant is shown in Fig. 1.

\subsection{ECCS strainers description and design}

Low pressure coolant injection (LPCI), low pressure core spray (LPCS) and high pressure core spray (HPCS) systems are used to inject water to the core in case of an emergency. The suctions of these systems are submerged in the suppression pool and have special strainers which filter the water from the suppression pool. Each suction line has two independent strainers as it is shown in Fig. 2.

The so-called "cassette" strainer was manufactured by CCI AG in Switzerland. The strainers are fully passive based on the following fundamental principles:

- The integration of the largest possible effective suction area into the smallest possible strainer volume, in order to achieve very small flow velocities.

- Modular design permitting different sizes of individual strainer units, as well as various combinations of strainer arrangements. With regard to this, Cofrentes has one strainer module smaller than the rest of the modules due to a mechanical restriction in the suppression pool and other plants have modules in row per suction line.

- Installation of suction strainers with a maximum suction area and with a large safety margin, compatible with the load

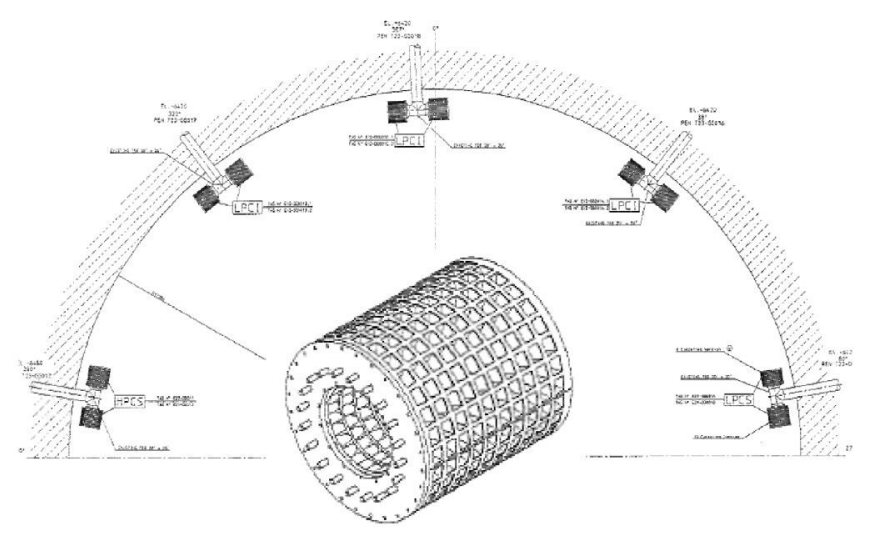

Fig. 2. ECCS strainer and its arrangement in the suppression pool. 


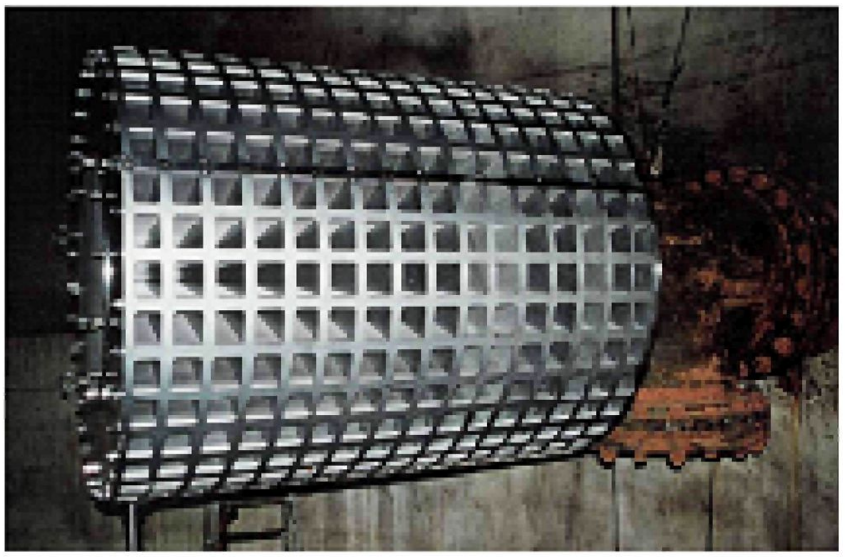

Fig. 3. ECCS module strainer.

bearing capacity, of the respective ECCS connections (flanges, nozzles, etc.).

The outer envelope of the strainer body is a jacket sheet with access windows leading to the inner structures as shown in Fig. 3. The internals have a large number of flow channel pockets which result in a very large effective suction area. The flange of the strainers allows direct connection to the ECCS suction nozzle flange. The pocket design leads to favorable pass through conditions for the water flow.

During a LOCA event, the suppression pool is highly turbulent. Debris from the containment, such as thermal isolation fibers, corrosion products, paint chips, rust and dust is transported to the suppression pool. The head loss across the debris bed formed on the strainer surface is the most important part of the ECCS strainer design. Several tests were implemented in the U.S.A. and Europe to measure head loss across the debris beds.

Consequently, several correlations were performed and collected in NUREG/CR-6224 (Zigler et al., 1995). For Cofrentes NPP, the expression used for incompressible mixed beds and for the specific NUKON fiber data was the following (English units):

$\Delta H=K_{T} \cdot\left[10(1+0.54 \eta)^{1.5} \cdot U+4(1+0.54 \eta) U^{2}\right] t^{1.33}$

where $\Delta H$ is the Strainer head loss (ft water), $K_{T}$ is the 0.299 (adimensional) $t$ is the theoretical thickness of fiber bed on the strainer (inch), $\eta$ is the Mc/Mf ratio, $U$ is the approach water velocity to the strainer (ft/s), Mc is the mass of corrosion products (lb), and Mf is the mass of fibrous debris (lb).

A list of considered debris for the design of the strainers at Cofrentes is shown in Table 1.

Table 1

Strainer design criterion for Cofrentes NPP.

\begin{tabular}{lll}
\hline Debris & Amount & Generation \\
\hline $\begin{array}{l}\text { Fiber thermal insulator } \\
\quad \text { Nukom) }\end{array}$ & $200 \mathrm{ft}^{3}(480 \mathrm{lb})$ & LOCA cofrentes invertory \\
$\begin{array}{l}\text { Metallic thermal insulator } \\
\text { (RMI) }\end{array}$ & $5685 \mathrm{ft}^{2}$ & \\
Paintings & & \\
Rust & $85 \mathrm{lb}$ & \\
Dirt & $50 \mathrm{lb}$ & LOCA URG NEDO-32686 \\
Unqualified paintings & $150 \mathrm{lb}$ & \\
Corrosion products & $12 \mathrm{~kg}$ & \\
Rust & $200.66 \mathrm{lb}$ & Normal operation \\
Paintings & $150.33 \mathrm{lb}$ & \\
\hline
\end{tabular}

The load of fiber in the strainer has great influence on its behavior. As a consequence, the correlation should be modified according to three different cases:

- Low fiber loading (LFL) case where the loading mass limit is $\mathrm{mf} \leq 0.14 \mathrm{lb} /$ pocket.

- Transition fiber loading (TFL) case where the loading mass limit is $\mathrm{mf} \approx 0.14$ up to $0.20 \mathrm{lb} /$ pocket.

- High fiber loading (HFL) case where the loading mass is $\mathrm{mf} \geq 0.20 \mathrm{lb} /$ pocket.

The HFL as conservative estimate was applied for the Cofrentes ECCS strainers. The equation is valid for water temperature $T_{w}=71 \pm 1^{\circ} \mathrm{F}$ but it can be adjusted proportionally to the water viscosity ratio.

Furthermore, the effect of different miscellaneous debris such as paint chips, rust flakes, LOCA generated cement dust, inorganic zinc particles is considered in the head loss calculation by means of "Bump-up Factor" methodology. This factor is calculated by computing the head loss due to fiber, corrosion products and miscellaneous debris at specified approach velocity divided by the head loss due to fiber and corrosion products alone, at the same approach velocity. Therefore the head loss from the miscellaneous debris is accounted for as a multiplicative factor which increases the total head loss.

$\Delta H_{\text {total }}=\Delta H_{\text {base }} \cdot K_{\text {bu }}$

where $K_{\mathrm{bu}}=\left[\Delta h_{x}\left(M_{\text {fiber }}, M_{\text {corrosion }}, M_{\text {rust }}, M_{\text {dust }}, \ldots\right)\right] /\left[\Delta h_{0}\left(M_{\text {fiber }}\right.\right.$, $\left.\left.M_{\text {corrosion, }}, M_{\text {rust }}=0, M_{\text {dust }}=0, \ldots\right)\right]$ potential issues related to ECCS strainer performance.

\subsection{BWR owners' group work}

Neither downstream effects nor chemical effects were noted in Bulletins 95-02 and 96-03. Significant improvements to PWR ECCS sump strainers have been made and final actions to close GL 200402 are in currently progress.

With GL 2004-02, the NRC requested that the boiling water reactor owners' group (BWROG) investigate differences between the methodologies used by the BWRs and PWRs to address the effects of post-LOCA debris on ECCS strainers, downstream equipment, and fuel.

Iberdrola, the owner of Cofrentes NPP is part of the BWROG (USA and International BWRs) and has contributed to the resolution of these studies through the BWROG ECCS Strainer Committee. More than twenty BWR plants constitute the BWROG committee so the coordination of the work is very complex because each plant has their specifics and refueling outage schedules.

The Committee is organized in four subcommittees:

1. Downstream effects fuel DSE-F.

2. Downstream effects components DSE-C.

3. Source term.

4. Headloss.

The BWROG work began making preliminary studies. One of these preliminary studies was to establish the differences between the new PWR methodology in relation to the old BWR methodology. The study comprised three topics:

- Regarding debris generation the most significant points are: PWR $P_{\text {destruct }}$ could be lower than BWR $P_{\text {destruct, }}$ taking into account unqualified coatings outside the zone of influence (ZOI), 
providing basis for latent debris quantity, providing basis for rust, and dust quantities.

- Regarding debris transport the most significant point is the difference among logic trees to determine the debris transport.

- Regarding head loss testing and analysis the most significant point is the introduction of more accurate measurements during the tests.

In case of the Cofrentes NPP during the design phase of the strainers a reasonable margin was considered because some conservatisms were introduced:

- All thermal insulators in the dry well could go to the suppression pool in case of LOCA and they will be in the suppression pool at the initial moment of the event.

- There was only one ZOI, the Dry Well.

- The transporting factor considered was 1 while the methodology had considered 0.5 .

- A variety of residues went to the strainers.

- The design took into account the manufacturer correlation (CCI) on behalf of the generic correlation (UGR). The correlation from the strainer manufacturer is more accurate than the URG because takes into account the specific characteristics of the plant.

Another preliminary study established by the BWROG was to complete different walkdowns in the Dry Well and the Primary Containment to confirm the debris load considered in the strainers design. There were four different walkdowns and their main characteristics were as follows:

1. Insulation: To identify and document (type, location, quantity) insulation, other fibrous materials, latent debris, and temporary equipment left in containment that may present a challenge to the ECCS strainer.

2. Coatings: To identify and document (type, quantity, condition) qualified and unqualified coatings that exist within the walkdown areas.

3. Latent debris: To collect dirt and dust debris samples.

4. Reactive materials: To review plant documents in order to establish the potential materials that could affect post-LOCA chemistry.

With regard to the walkdowns, Cofrentes NPP completed them during the refueling outage in 2009 and 2011 and the fuel cycle between them. The following measurements were performed:

- A plan was established to substitute the NUKON thermal isolation made of fibers with metallic thermal isolation. From 1999 to nowadays each refueling outage a portion of NUKON isolation is substituted although margin for this component is very high.

- The suppression pool was cleaned, as shown in Fig. 4, and the frequency for this cleaning was updated.

- Potential materials were detected in the Containment and Dry Well that could fall in the suppression pool so they were eliminated or substituted to another qualified material.

- The metallic thermal insulation was review.

- The paintings were reviewed and repaired in some cases.

- The personal safety signs, fire signage, and radiological labels were substituted with painted signs.

- The identification of the equipment was substituted with qualified metallic identifications.

- The Foreign Material Exclusion procedure was updated.

- Cabinets to collect the operational assistant papers were installed.

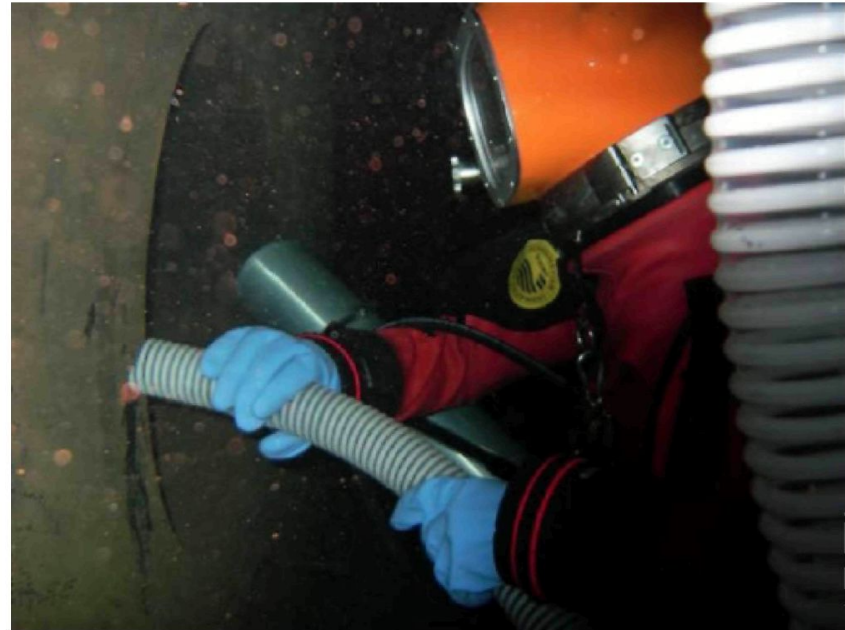

Fig. 4. Suppression pool cleaning.

- The Containment was cleaned with greater precision as shown in Fig. 5 in 2009 and 2010, During the refueling outage in 2011 the Dry Well was cleaned in the same way.

- There is a plan to substitute plastic loudspeakers with metallic ones.

- There is a plan to register the aluminum equipment.

- There is a plan to qualify tags for the Dry Well.

Furthermore, the BWROG performed a guideline which provides site engineering personnel with a means to evaluate conditions identified by the debris source term walkdowns in support of operability determinations. According to this, Cofrentes could sufficiently ensure that their margins are totally enough taking into account the walkdowns performed. Studies performed to demonstrate this fact showed the following considerations:

- The collected debris during walkdowns was at most half of the limited debris calculated for the strainer.

- The NPSH (Net Positive Suction Head) required for the pumps was at least three times lower than the NPSH available, as shown in Fig. 6. Fluid will only flow into the pump head by atmospheric pressure or atmospheric pressure plus a positive suction head. If suction pressure at suction pipe is below the vapor pressure of the fluid, the fluid may flash into a vapor. For satisfactory pump

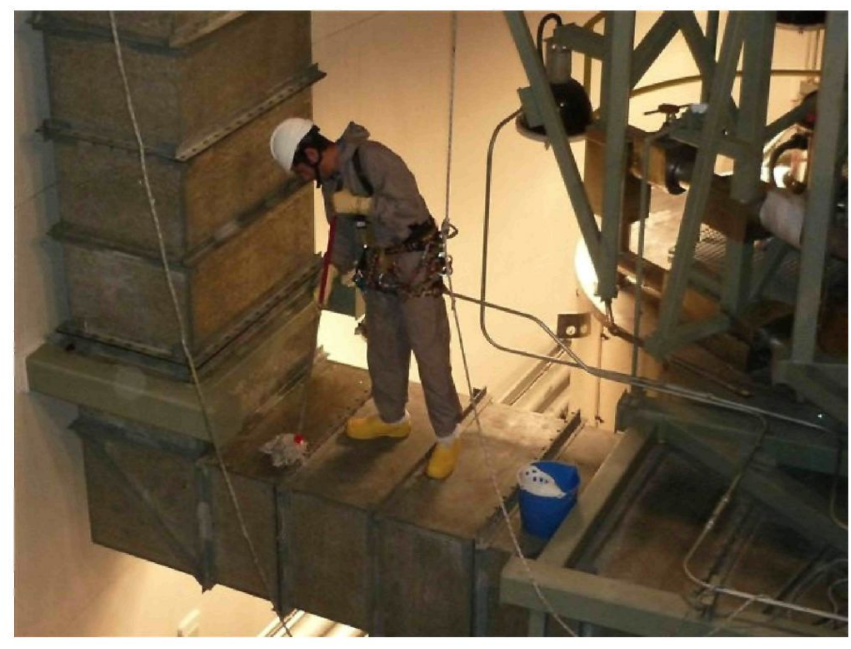

Fig. 5. Containment cleaning. 


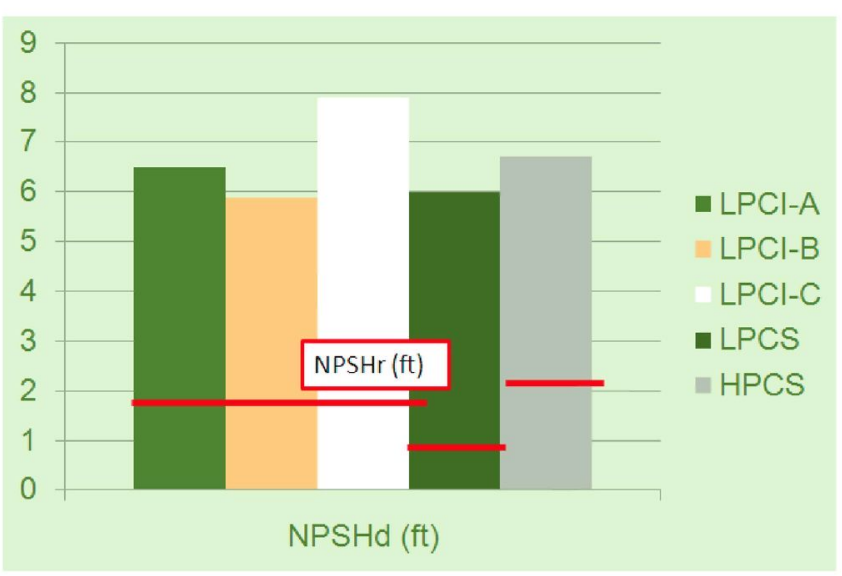

Fig. 6. NPSH required and available per each pump.

operation under any set of conditions (capacity versus head) the NPSH, available, must be greater than the NPSH required.

- The limited amount per each kind of debris was considerably higher than the current debris collected.

The third preliminary study which is now in process will consist of an ECCS strainer bypass test. The purpose of these bypass tests will be to determine the quantity and characteristics of fibrous debris that can potentially pass through the small holes of the perforated plate surface of the strainers in a post-LOCA environment. The bypass debris could affect downstream components like valves, heat exchangers or seals and/or accumulate in the reactor core and challenge the long term core cooling requirements following a loss of coolant accident (LOCA).

For these tests, Cofrentes was in contact with the strainer manufacturer and could send a representative strainer to the designated facility at the request of the committee, if needed.

This study was performed during 2012 for two different designs of strainers. As it was previously mentioned there are more than twenty BWR involved plants. It means that there are at least four different designs of strainers. To achieve representing results for every plant one strainer with complex geometry and another one with simple design was selected to the test. Several water approach velocities, types and concentrations of fibers were tested to achieve a general view of the performance of the strainer for all kind of circumstances. The BWROG is analyzing and compiling the results and it hopes to issue a final report during 2013.

\subsection{The twelve issues}

All of these studies are necessary to solve the main issues. The majority of them need the results of these preliminary studies to progress or these studies form an important part of the necessary work for each issue.

Nowadays, the BWRs are studying 12 different points to resolve all the issues related to the ECCS strainer performance:

\section{Downstream effects for components and systems:}

Debris materials that pass through strainers might block very small openings in valves, pumps or other ECCS components so this point deals with the evaluation of this phenomenon. Furthermore, debris material that passes through strainers might produce erosive or abrasive wear of ECCS components.
The objective of this point will be to demonstrate the good performance of any BWR fuel with regard to the effect of downstream considered LOCA debris. These days this is one of the most important issues so tests will begin in 2013. Fuel from the three vendors which has their fuel in BWR reactors will be tested.

\section{Debris head loss predictions:}

The treatment of different debris in the correlations could not have been conservative. The objective of this point will be to provide generic assessment of validity of existing plant correlations.

\section{Chemical effects:}

The regulators require licensees to assess the impact of the chemical environment on the ability of the ECCS to provide longterm core cooling so this point will focus on corrosion products, metallic components made of aluminum like microporous insulation and concrete.

\section{Assessment of coatings:}

Non-qualified coatings inventories could be greater than the established so the introduction of assessment programs and address changes to the unqualified coatings inventory will be necessary.

\section{Latent debris:}

Regulators noted that the BWR methodology assumed that latent debris was compounded solely of particles with a total Dry Well quantity of $150 \mathrm{lb}$. Now a requirement on the validation of this quantity and guidance on size characteristic is required.

\section{ZOI adjustment for air jet testing:}

Debris generation in the zones of influence (ZOI) is based on debris generation test conducted with air. Now there is a concern that steam may be more destructive than air so an increase in the size of the ZOIs could be required.

\section{ZOI for protective coatings:}

The BWR evaluation method could be not sufficiently conservative so more tests will be needed.

\section{Debris transport and erosion:}

The regulators noted differences between the PWR and BWR guidance which are necessary to evaluate. The objective of this point will be to develop a position paper confirming the validity of the BWR methodology.

\section{Debris characteristics:}

Potential blockage of calcium silicate insulation and other problematic materials such as microporous insulation could not have been conservatively treated. The objective of this point will be to identify acceptable debris characteristics for use in BWR strainer qualification analysis and testing. After that, plants could compare their analysis with the guidance document. 
Settling of debris materials on test tank surfaces was noted in some PWR strainer test. As a consequence, assurance of any deposit material during tests is required for BWR plants.

\section{Spherical ZOI:}

Spherical ZOI could have maximized the quantity of debris but could not have selected the most problematic debris, such as microporous or calcium silicate insulation. The objective of this point is to assess conservative spherical ZOI.

\section{Conclusion}

The work is very complex and it progress slowly. There are several involved plants with very different refueling outage schedules and special characteristics. Furthermore, interaction with regulators is very close and each result and point is agree on together.

Cofrentes is cooperating with the BWROG to resolve all the issues. The studies are going to address the effects of post-LOCA debris on ECCS strainers, downstream equipment and fuel, resolve those differences and recalculate the safety margins of the strainers to ensure their performance.

In case of Cofrentes, several conservative estimates were taken into account for the design of the strainers during the 90s. Head loss in the strainers and NPSH available in the pumps have a wide margin. In spite of this new phenomenon were not analyzed during the 90 s. The BWROG has a plan to study every phenomena including real tests and a common solution will be issued for the fleet of BWR in the USA and for international members. As a result, Cofrentes continues to cooperate.

Meanwhile the BWROG achieves final results for all these issues, Cofrentes updates their procedures to increase control about foreign materials in the Containment and Dry Well, maintains the cleanliness of these parts and the suppression pool, continues with plans to substitute NUKON isolation and establishes additional controls for reactive materials in that buildings.

New bigger ECCS strainers installed at Cofrentes in 1999 together all these measurements are a warranty to maintain a great safety ECCS strainer performance in case of an emergency. 